\title{
KEPUASAN PENGGUNA WIKA SOLAR WATER HEATER MENGGUNAKAN METODE IMPORTANCE PERFORMANCE ANALYSIS DAN CUSTOMER SATISFACTION INDEX PADA CV VANIA JAYA PLUMBING
}

\author{
Andre Irvani' ${ }^{1}$, Muhammad \\ Arif $^{2}$, Hanifatul Rahmi ${ }^{3}$ \\ ${ }^{1)}$ Program Studi Teknik Industri, Sekolah \\ Tinggi Teknologi Dumai \\ Jl. Utama Karya Bukit Batrem II \\ Email: andreirvan30@gmail.com; \\ pakarifmt@gmail.com; \\ hanifatulrahmi@sttdumai.ac.id
}

\begin{abstract}
ABSTRAK
Wika Solar Water Heater merupakan pemanas air yang memanfaatkan tenaga matahari sebagai sumber energi yang aman dan ramah lingkungan. Produk wika solar water heater ditujukan untuk keperluan perumahan/residensial dan komersial seperti Hotel, Apartemen, Rumah Sakit, Industri dan sebagainya. Banyaknya perusahaan lain yang menawarkan produk dalam bisnis water heater saat ini menimbulkan permasalahan yang harus dihadapi oleh pihak perusahaan. Hal utama dalam permasalahan yang dihadapi seperti kualitas layanan yang diberikan oleh pihak perusahaan kepada pelanggan. Berdasarkan data tersebut peneliti merasa perlu dilakukannya penelitian untuk mengevaluasi tingkat kepuasan pelanggan, metode yang dapat digunakan diantaranya Importance performance analysis (IPA) dan Customer Statisfaction Index (CSI). Importance performance analysis memiliki beberapa kelebihan dibandingkan dengan metode lain. Hasil dari penelitian ini Peneliti memperoleh nilai IPA untuk sumbu x sebesar 3,36 dan nilai untuk sumbu y sebesar 3,38. Sedangkan untuk nilai CSI sebesar 0,672 atau 67,2\% yang berarti pada kisaran antara 0,61-0,80. Berdasarkan hasil CSI tersebut, maka kualitas pelayanan pada CV Vania Jaya Plumbing tersebut merasa puas terhadap kualitas pelayanan yang diberikan oleh karyawan selama ini.
\end{abstract}

Kata kunci: CSI, IPA, Wika Solar Water Heater.

\section{ABSTRACT}

Wika Solar Water Heater is a water heater that utilizes solar energy as a safe and environmentally friendly energy source. Wika solar water heater products are intended for residential/residential and commercial purposes such as hotels, apartments, hospitals, industries and so on. The number of other companies that offer products in the water heater business is currently causing problems that must be faced by the company. The main thing in the problems faced is the quality of services provided by the company to customers.

Based on these data, the researcher feels the need to conduct research to evaluate the level of customer satisfaction, methods that can be used include Importance Performance Analysis (IPA) and Customer Statisfaction Index (CSI). Importance performance analysis has several advantages compared to other methods. The results of this study Researchers obtained the IPA value for the $x$-axis of 3.36 and the value for the $y$-axis of 3.38. As for the CSI value of 0.672 or $67.2 \%$ which means in the range between 0.61-0.80. Based on the results of the CSI, the quality of service at CV Vania Jaya Plumbing is satisfied with the quality of service provided by employees so far.

Keywords: CSI, IPA Wika Solar Water Heater. 


\section{Pendahuluan}

Wika Solar Water Heater merupakan pemanas air yang memanfaatkan tenaga matahari sebagai sumber energi yang aman dan ramah lingkungan. Produk wika solar water heater ditujukan untuk keperluan perumahan/residensial dan komersial seperti Hotel, Apartemen, Rumah Sakit, Industri dan sebagainya. CV Vania Jaya Plumbing merupakan badan usaha yang bergerak di bidang jasa untuk pemasangan dan perbaikan serta perawatan produk Wika Solar Water Heater yang diproduksi oleh PT Wika Industri Energi. CV Vania Jaya Plumbing berdiri sejak tahun 2019 dan telah menyelesaikan pesanan dari 67 pelangan dengan total 430 titik pemasangan wika solar water heater. Banyaknya perusahaan lain yang menawarkan produk dalam bisnis water heater saat ini menimbulkan permasalahan yang harus dihadapi oleh pihak perusahaan. Hal utama dalam permasalahan yang dihadapi seperti kualitas layanan yang diberikan oleh pihak perusahaan kepada pelanggan. Pihak perusahaan juga dituntut untuk cepat dan tanggap dalam menangani keluhan yang dilakukan pelanggan, supaya pelanggan bisa merasakan kepuasan atas pelayanan penanganan keluhan yang dirasakan, sehingga pelanggan bisa menjadi loyal terhadap perusahaan. Untuk meraih kesuksesan dalam persaingan, perusahaan harus mampu memberikan tingkat kualitas pelayanan yang baik agar pelanggan merasa puas dengan produk yang ditawarkan.

Berdasarkan data tersebut peneliti merasa perlu dilakukannya penelitian untuk mengevaluasi tingkat kepuasan pelanggan, metode yang dapat digunakan diantaranya Importance performance analysis (IPA) dan Customer Statisfaction Index (CSI). Importance performance analysis memiliki beberapa kelebihan dibandingkan dengan metode lain. Kelebihan tersebut antara lain dapat menunjukkan atribut produk/jasa yang perlu ditingkatkan ataupun dikurangi untuk menjaga kepuasan konsumen, hasilnya relatif mudah diinterpretasikan, skalanya relatif mudah dimengerti, dan membutuhkan biaya yang rendah. Sedangkan Customer Statisfaction Index (CSI) memiliki beberapa keunggulan antara lain efisiensi (tidak hanya indeks kepuasan tetapi sekaligus memperoleh informasi yang berhubungan dengan dimensi/atribut yang perlu diperbaiki), mudah digunakan dan sederhana serta menggunakan skala yang memiliki sensitivitas dan reliabilitas cukup tinggi.

\section{Metode Penelitian}

Penelitian dilakukan CV Vania Jaya Plumbing beralamat di jalan Soekarno-Hatta, Dumai yang dilakukan pada bulan Agustus 2021 sampai Oktober 2021. Populasi dan sampel dari penelitian ini adalah pelanggan yang menggunakan wika solar water heater yang dikerjakan oleh CV Vania Jaya Plumbing sebanyak 65 orang. Dalam. penelitian ini cara yang digunakan untuk pengambilan data adalah kuesioner dan kepustakan. Pengolahan data berdasarkan metode Importance Performance Analysis yaitu, Menghitung tingkat kesesuaian antara tingkat kinerja dan harapan, menghitung skor rata-rata kinerja dan harapan, menghitung skor rata-rata atribut tingkat kinerja dan harpaan, pemetaan rata-rata setiap atribut ke dalam diagram kartesius. Sedangkan pengolahan data menggunakan metode Customer Satisfaction Index yaitu, menentukan mean importance score (MIS) dan mean satisfaction score (MSS), menghitung weight factor (WF), menghitung weight score (WS), menghitung nilai customer satisfaction index (CSI). 


\section{Hasil dan Pembahasan}

Uji Validasi windows.

Untuk pengujian validasi dilakukan dengan program SPSS versi 25 for

Tingkat Signifikan

$$
\begin{array}{ll}
\alpha & =0,05 \\
\text { Df } & =n-2 \\
& =65-2 \\
\text { r table } & =63 \\
& =0,2441
\end{array}
$$

Hasil uji validasi skor kinerja atau sumbu x dan sumbu y dapat dilihat pada Tabel 1.

Tabel 1. Uji Validasi Skor Kinerja

\begin{tabular}{|c|c|c|r|c|}
\hline Variabel & $\mathrm{r}$ tabel & $\mathrm{r}$ hitung sumbu $\mathrm{x}$ & $\mathrm{r}$ hitung sumbu $\mathrm{y}$ & Ket \\
\hline $\mathrm{X}_{1}$ & 0,2441 & 0,2480 & 0,3280 & Valid \\
\hline $\mathrm{X}_{2}$ & 0,2441 & 0,4400 & 0,3170 & Valid \\
\hline $\mathrm{X}_{3}$ & 0,2441 & 0,4030 & 0,3720 & Valid \\
\hline $\mathrm{X}_{4}$ & 0,2441 & 0,3520 & 0,3450 & Valid \\
\hline $\mathrm{X}_{5}$ & 0,2441 & 0,5030 & 0,3300 & Valid \\
\hline $\mathrm{X}_{6}$ & 0,2441 & 0,4370 & 0,3680 & Valid \\
\hline $\mathrm{X}_{7}$ & 0,2441 & 0,5120 & 0,3260 & Valid \\
\hline $\mathrm{X}_{8}$ & 0,2441 & 0,3510 & 0,3270 & Valid \\
\hline $\mathrm{X}_{9}$ & 0,2441 & 0,3130 & 0,3450 & Valid \\
\hline $\mathrm{X}_{10}$ & 0,2441 & 0,5130 & 0,3350 & Valid \\
\hline $\mathrm{X} 11$ & 0,2441 & 0,3180 & 0,3120 & Valid \\
\hline $\mathrm{X} 12$ & 0,2441 & 0,3390 & 0,3480 & Valid \\
\hline $\mathrm{X} 13$ & 0,2441 & 0,3380 & 0,2900 & Valid \\
\hline $\mathrm{X} 14$ & 0,2441 & 0,4240 & 0,2810 & Valid \\
\hline $\mathrm{X} 15$ & 0,2441 & 0,3230 & 0,3580 & Valid \\
\hline $\mathrm{X} 16$ & 0,2441 & 0,4200 & 0,4170 & Valid \\
\hline
\end{tabular}

Sumber: Pengolahan Data, 2021

Uji Reabilitas

Pengujian reabilitas dilakukan menggunakan program SPSS versi 25 for windows. Hasil uji reabilitas pada CV Vania Jaya Plumbing dapat dilihat pada Tabel 2.

Tabel 2. Uji Reabilitas Sumbu X dan Y Pada CV Vania Jaya Plumbing

\begin{tabular}{|c|r|r|r|}
\hline Reabilitas & $\begin{array}{c}\text { Koofesien } \\
\text { Alpha }\end{array}$ & \multicolumn{1}{|c|}{$\begin{array}{c}\text { Nilai Batas } \\
\text { Bawah }\end{array}$} & Keterangan \\
\hline $\mathrm{X}$ & 0,688 & 0,6 & Reliabel \\
\hline $\mathrm{Y}$ & 0, & 0,6 & Reliabel \\
\hline
\end{tabular}

Sumber: Pengolahan Data, 2021

Berdasarkan Tabel 2 dapat ditunjukan bahwa nilai hasil reabilitas masingmasing sumbu $>0.6$ (nilai Cronbach Alpha), maka dari hasil ini dapat diperoleh kesimpulan bahwa semua variabel pada kuesioner tersebut dinyatakan Reliabel.

Analisis Tingkat Kesesuaian Atribut 
1. Menghitung skor kinerja dan kepentingan

Contoh perhitungan skor kinerja dan harapan diambil dari atribut apakah petunjuk informasi tentang proses pendaftaran sudah jelas.

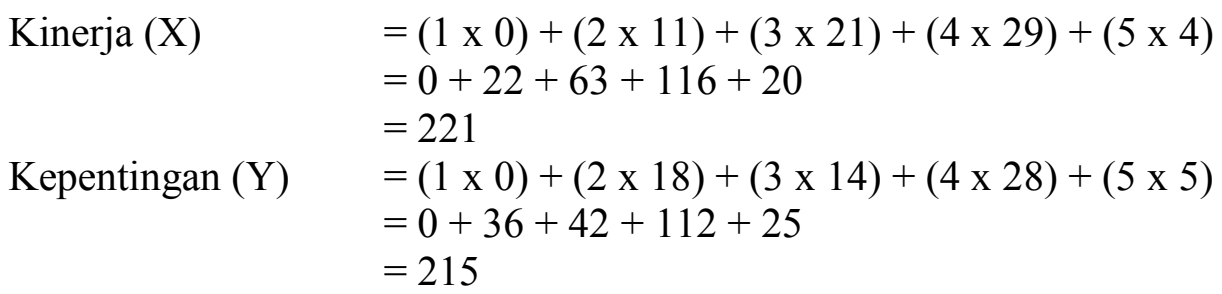

\section{Menghitung tingkat kesesuaian}

Contoh perhitungan tingkat kesesuaian diambil dari atribut apakah petunjuk informasi tentang proses pendaftaran sudah jelas.

Tingkat kesesuaian (\%)

$$
\begin{aligned}
& =(221: 215) \times 100 \% \\
& =102,79 \%
\end{aligned}
$$

Rata-rata tingkat kesesuaian (\%)

$$
\begin{aligned}
& =(102,79+100,00+96,88+97,25+\ldots . .+112,14+97,62) \\
& =99,70 \%
\end{aligned}
$$

Tabel 3. Tingkat Kesesuaian Kinerja dan Kepentingan

\begin{tabular}{|r|l|r|r|r|c|}
\hline No & \multicolumn{1}{|c|}{ Atribut } & $\begin{array}{c}\text { Tingkat } \\
\text { Kinerja } \\
(\mathrm{Ki})\end{array}$ & $\begin{array}{c}\text { Tingkat } \\
\text { Kepentingan } \\
(\mathrm{Hi})\end{array}$ & $\begin{array}{c}\text { Tingkat } \\
\text { Kesesuaian } \\
\text { (Tki)\% }\end{array}$ & $\begin{array}{c}\text { Hold } \\
\text { and } \\
\text { Action }\end{array}$ \\
\hline 1 & $\begin{array}{l}\text { Apakah petunjuk informasi tentang proses } \\
\text { pendaftaran sudah jelas? }\end{array}$ & 221 & 215 & $102,79 \%$ & $\mathrm{H}$ \\
\hline 2 & $\begin{array}{l}\text { Apakah karyawan berpenampilan rapi saat } \\
\text { bekerja? }\end{array}$ & 226 & 226 & $100,00 \%$ & $\mathrm{H}$ \\
\hline 3 & Apakah peralatan yang digunakan lengkap? & 217 & 224 & $96,88 \%$ & $\mathrm{~A}$ \\
\hline 4 & $\begin{array}{l}\text { Apakah prosedur laporan kepada pelanggan } \\
\text { sudah jelas? }\end{array}$ & 212 & 218 & $97,25 \%$ & $\mathrm{~A}$ \\
\hline 5 & Apakah proses pengerjaan cepat dan akurat? & 206 & 202 & $101,98 \%$ & $\mathrm{H}$ \\
\hline 6 & Apakah proses dalam pembayaran mudah? & 213 & 226 & $94,25 \%$ & $\mathrm{~A}$ \\
\hline 7 & $\begin{array}{l}\text { Apakah karyawan siap membantu bila } \\
\text { pelanggan mengalami kesulitan? }\end{array}$ & 218 & 234 & $93,16 \%$ & $\mathrm{~A}$ \\
\hline 8 & $\begin{array}{l}\text { Apakah karyawan cepat dalam memberikan } \\
\text { informasi yang dibutuhkan? }\end{array}$ & 211 & 222 & $95,05 \%$ & $\mathrm{~A}$ \\
\hline 9 & $\begin{array}{l}\text { Apakah peralatan yang digunakan bersih } \\
\text { dalam proses pengerjaan? }\end{array}$ & 226 & 221 & $102,26 \%$ & $\mathrm{H}$ \\
\hline 10 & $\begin{array}{l}\text { Apakah paket harga yang ditawarkan } \\
\text { terjangkau? }\end{array}$ & 214 & 225 & $95,11 \%$ & $\mathrm{~A}$ \\
\hline 11 & $\begin{array}{l}\text { Apakah biaya jasa yang ditawarkan sesuai } \\
\text { dengan kualitas? }\end{array}$ & 228 & 216 & $105,56 \%$ & $\mathrm{H}$ \\
\hline 12 & $\begin{array}{l}\text { Apakah hasil pengerjaan tepat dan akurat? } \\
13\end{array}$ & $\begin{array}{l}\text { Apakah karyawan ahli dalam bidangnya dan } \\
\text { sudah berpengalaman? }\end{array}$ & 228 & $99,56 \%$ & $\mathrm{~A}$ \\
\hline
\end{tabular}


Tabel 3. Tingkat Kesesuaian Kinerja dan Kepentingan (Lanjutan)

\begin{tabular}{|c|c|c|c|c|c|}
\hline No & Atribut & $\begin{array}{l}\text { Tingkat } \\
\text { Kinerja } \\
(\mathrm{Ki})\end{array}$ & $\begin{array}{l}\text { Tingkat } \\
\text { Kepentingan } \\
\text { (Hi) }\end{array}$ & $\begin{array}{l}\text { Tingkat } \\
\text { Kesesuaian } \\
\text { (Tki) } \%\end{array}$ & $\begin{array}{l}\text { Hold } \\
\text { and } \\
\text { Action }\end{array}$ \\
\hline 14 & $\begin{array}{l}\text { Apakah karyawan menanyakan posisi } \\
\text { peletakan wika solar water heater yang tepat } \\
\text { dan sesuai dengan keinginan pelanggan? }\end{array}$ & 229 & 208 & $110,10 \%$ & $\mathrm{H}$ \\
\hline 15 & $\begin{array}{l}\text { Apakah karyawan selalu menerapkan salam, } \\
\text { senyum dan sapa? }\end{array}$ & 231 & 206 & $112,14 \%$ & $\mathrm{H}$ \\
\hline 16 & $\begin{array}{l}\text { Apakah SOP dalam penggunaan wika solar } \\
\text { water heater sudah jelas dan tersedia? }\end{array}$ & 205 & 210 & $97,62 \%$ & A \\
\hline \multicolumn{4}{|c|}{ Rata-rata } & $99,70 \%$ & \\
\hline
\end{tabular}

Sumber: Pengolahan Data, 2021

Nilai skor pengambilan keputusan akan dibandingkan dengan tingkat kesesuaian, apabila nilai tingkat kesesuaian kecil dari nilai skor pengambilan keputusan maka atribut tersebut perlu adanya perbaikan (Action) dan bila tingkat kesesuaian lebih besar dari skor pengambilan keputusan maka atribut tersebut perlu dipertahankan (Hold) dengan ketentuan.

1. Jika tingkat kesesuaian kecil dari 99,70 maka perlu adanya perbaikan yang ditandai dengan huruf A (Action)

2. Jika tingkat kesesuaian besar dari 99,70 maka perusahaan perlu mempertahankan atribut tersebut yang ditandai dengan huruf $\mathrm{H}$ (Hold)

Setelah dilakukan tingkat kesesuaian antara tingkat kinerja dan tingkat kepentingan, selanjutnya perhitungan rata-rata untuk menentukan koordinat pada diagram kartesius. Hasil perhitungan rata-rata untuk tingkat kinerja (x) dan tingkat kepentingan (y) dapat dilihat pada Tabel 4.

Tabel 4. Nilai Diagram Kartesius

\begin{tabular}{|r|l|r|r|}
\hline No & \multicolumn{1}{|c|}{ Atribut } & \multicolumn{1}{|c|}{$\begin{array}{c}\text { Tingkat } \\
\text { Kinerja (Ki) }\end{array}$} & $\begin{array}{c}\text { Tingkat } \\
\text { Kepentingan (Hi) }\end{array}$ \\
\hline 1 & $\begin{array}{l}\text { Apakah petunjuk informasi tentang proses pendaftaran sudah } \\
\text { jelas? }\end{array}$ & 3,40 & 3,31 \\
\hline 2 & Apakah karyawan berpenampilan rapi saat bekerja? & 3,48 & 3,48 \\
\hline 3 & Apakah peralatan yang digunakan lengkap? & 3,34 & 3,45 \\
\hline 4 & Apakah prosedur laporan kepada pelanggan sudah jelas? & 3,27 & 3,35 \\
\hline 5 & Apakah proses pengerjaan cepat dan akurat? & 3,17 & 3,11 \\
\hline 6 & Apakah proses dalam pembayaran mudah? & 3,28 & 3,60 \\
\hline 7 & $\begin{array}{l}\text { Apakah karyawan siap membantu bila pelanggan mengalami } \\
\text { kesulitan? }\end{array}$ & 3,36 & 3,42 \\
\hline 8 & $\begin{array}{l}\text { Apakah karyawan cepat dalam memberikan informasi yang } \\
\text { dibutuhkan? }\end{array}$ & 3,25 & 3,40 \\
\hline 9 & $\begin{array}{l}\text { Apakah peralatan yang digunakan bersih dalam proses } \\
\text { pengerjaan? }\end{array}$ & 3,48 & 3,46 \\
\hline 10 & Apakah paket harga yang ditawarkan terjangkau? & 3,30 & 3,32 \\
\hline 11 & Apakah biaya jasa yang ditawarkan sesuai dengan kualitas? & 3,51 & 3,52 \\
\hline 12 & Apakah hasil pengerjaan tepat dan akurat? & 3,51 & 3,60 \\
\hline 13 & $\begin{array}{l}\text { Apakah karyawan ahli dalam bidangnya dan sudah } \\
\text { berpengalaman? }\end{array}$ & 3,30 & \\
\hline
\end{tabular}


Tabel 4. Nilai Diagram Kartesius

\begin{tabular}{|r|l|r|r|}
\hline No & \multicolumn{1}{|c|}{ Atribut } & $\begin{array}{c}\text { Tingkat } \\
\text { Kinerja (Ki) }\end{array}$ & $\begin{array}{c}\text { Tingkat } \\
\text { Kepentingan (Hi) }\end{array}$ \\
\hline 14 & $\begin{array}{l}\text { Apakah karyawan menanyakan posisi peletakan wika solar } \\
\text { water heater yang tepat dan sesuai dengan keinginan } \\
\text { pelanggan? }\end{array}$ & 3,53 & 3,20 \\
\hline 15 & $\begin{array}{l}\text { Apakah karyawan selalu menerapkan salam, senyum dan } \\
\text { sapa? }\end{array}$ & 3,56 & 3,17 \\
\hline 16 & $\begin{array}{l}\text { Apakah SOP dalam penggunaan wika solar water heater } \\
\text { sudah jelas dan tersedia? }\end{array}$ & 3,16 & 3,23 \\
\hline \multicolumn{2}{|c|}{ Rata-rata } & 3,36 & 3,38 \\
\hline
\end{tabular}

Sumber: Pengolahan data, 2021

Analisis Diagram Kartesius

Diagram kartesius merupakan suatu diagram yang dibagi atas empat bagian yang dibatasi oleh dua buah garis yang berpotongan tegak lurus pada titik-titik $(\mathrm{X}, \mathrm{Y})$ dengan $\mathrm{X}$ merupakan rata-rata dari rata-rata skor tingkat kinerja dan $\mathrm{Y}$ adalah rata-rata dari ratarata skor tingkat kepentingan seluruh faktor yang mempengaruhi kepuasan pelanggan. Diagram kartesisus pada Gambar 1 menjelaskan posisi masing-masing atribut yang mempengaruhi tingkat kepuasan konsumen terbagi ke dalam empat kuadran.

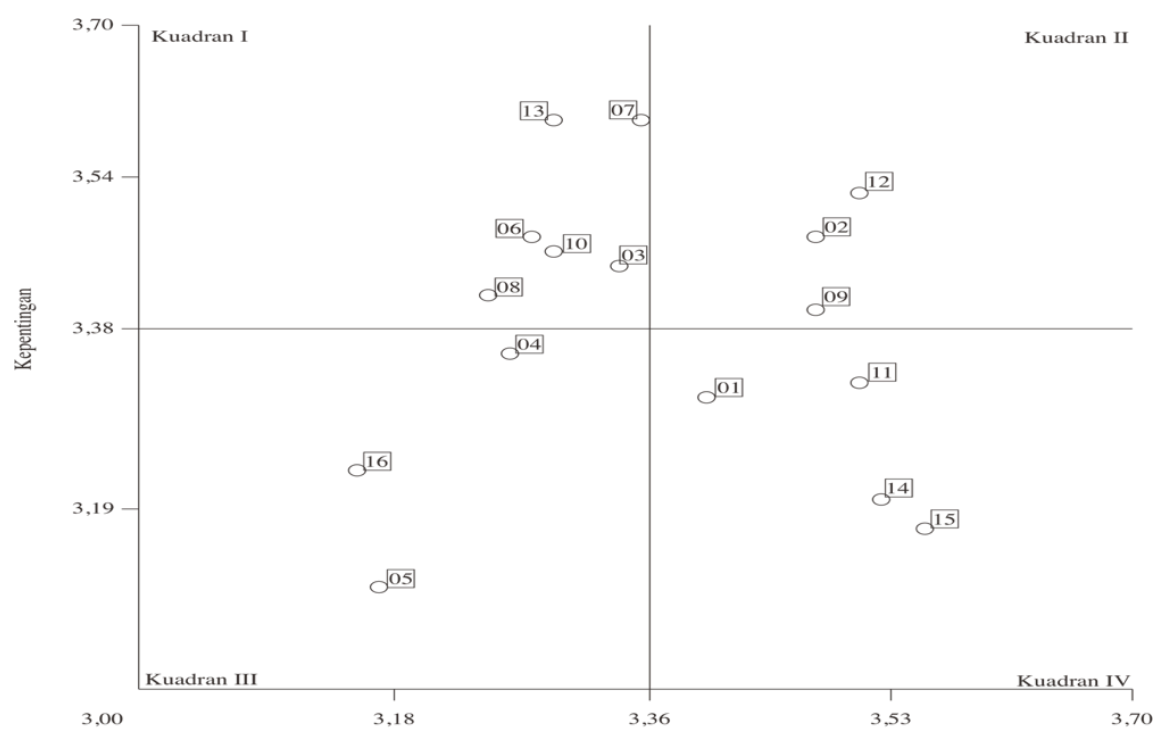

Gambar 1. Diagram kartesius kinerja dan harapann

Sumber: Pengolahan data, 2021

Perhitungan Customer Satisfaction Index (CSI)

Adapun perhitungan mean satisfaction score pada atribut $\left(\mathrm{X}_{1}\right)$ sebagai berikut:

$M S S i=\frac{\sum x i}{n}$

$M S S i=\frac{221}{65}$

$M S S i=3,40$

Adapun perhitungan mean importance score pada atribut $\left(\mathrm{Y}_{1}\right)$ sebagai berikut:

$M I S i=\frac{\sum y i}{n}$ 
$M I S i=\frac{215}{65}$

MISi $=3,31$

Hasil perhitungan Customer Satisfaction Index (CSI) dapat dilihat pada Tabel 5.

Tabel 5. Rekapitulasi nilai MISi dan MSSi

\begin{tabular}{|r|r|r|r|r|}
\hline \multicolumn{1}{|c|}{ No } & Total Kinerja $\left(\sum\right.$ MSS $)$ & Nilai MSS & Total Kepentingan $\left(\sum\right.$ MIS) & \multicolumn{1}{l|}{ Nilai MIS } \\
\hline 1 & 221 & 3,40 & 215 & 3,31 \\
\hline 2 & 226 & 3,48 & 226 & 3,48 \\
\hline 3 & 217 & 3,34 & 224 & 3,45 \\
\hline 4 & 212 & 3,26 & 218 & 3,35 \\
\hline 5 & 206 & 3,17 & 202 & 3,11 \\
\hline 6 & 213 & 3,28 & 226 & 3,48 \\
\hline 7 & 218 & 3,35 & 234 & 3,60 \\
\hline 8 & 211 & 3,25 & 222 & 3,42 \\
\hline 9 & 226 & 3,48 & 221 & 3,40 \\
\hline 10 & 214 & 3,29 & 225 & 3,46 \\
\hline 11 & 228 & 3,51 & 216 & 3,32 \\
\hline 12 & 228 & 3,51 & 229 & 3,52 \\
\hline 13 & 214 & 3,29 & 234 & 3,60 \\
\hline 14 & 229 & 3,52 & 208 & 3,20 \\
\hline 15 & 231 & 3,55 & 206 & 3,17 \\
\hline 16 & 205 & 3,15 & & 3,23 \\
\hline Total & & 53,84 & & 54,09 \\
\hline Sul
\end{tabular}

Sumber: Pengolahan Data, 2021

Perhitungan Weight Factors (WF)

$\sum M I S i=M I S_{1}+M I S_{2}+M I S_{3}+M I S_{4}+\ldots . M I S_{15}+M I S_{16}$

$\sum M I S i=3,31+3,48+3,45+3,35+\ldots .+3,17+3,23$

$\sum M I S i=54,09$

$W F i=\frac{M I S i}{\sum_{3,31} M I S i}$

$W F i=\frac{3,31}{54,09}$

$W F i=0,0611$

Perhitungan Weight Score (WS)

Perhitungan weight score merupakan perkalian atara WF dengan rata-rata tingkat kepuasan atau mean satisfaction score (MSS).

WSi $=$ WFi $\times$ MSSi

$\mathrm{WSi}=6,11 \% \times 3,40$

$=0,21$

Rekapitulasi hasil perhitungan weight factor dan weight score yang dapat dilihat pada Tabel 6 sebagai berikut: 
Tabel 6. Weight Score

\begin{tabular}{|r|r|r|}
\hline \multicolumn{1}{|c|}{ No } & Nilai WF & \multicolumn{1}{c|}{ Nilai WS } \\
\hline 1 & $6,11 \%$ & 0,21 \\
\hline 2 & $6,43 \%$ & 0,22 \\
\hline 3 & $6,37 \%$ & 0,21 \\
\hline 4 & $6,20 \%$ & 0,20 \\
\hline 5 & $5,75 \%$ & 0,18 \\
\hline 6 & $6,43 \%$ & 0,21 \\
\hline 7 & $6,66 \%$ & 0,22 \\
\hline 8 & $6,31 \%$ & 0,21 \\
\hline 9 & $6,29 \%$ & 0,22 \\
\hline 10 & $6,40 \%$ & 0,21 \\
\hline 11 & $6,14 \%$ & 0,22 \\
\hline 12 & $6,51 \%$ & 0,23 \\
\hline 13 & $6,66 \%$ & 0,22 \\
\hline 14 & $5,92 \%$ & 0,21 \\
\hline 15 & $5,86 \%$ & 0,21 \\
\hline 16 & $5,97 \%$ & 0,19 \\
\hline Total & $100 \%$ & 3,36 \\
\hline
\end{tabular}

Sumber: Pengolahan Data, 2021

Perhitungan Nilai Customer Satisfaction Index (CSI)

Nilai persentase CSI dihitung dengan membagi weight score dengan skala maksimum yang digunakan.

$\mathrm{CSI}=\frac{\sum \mathrm{WS}}{\mathrm{HS}}$

$\sum \mathrm{WS}=$ Total Weight Score

HS = Heighest scale atau skala maksimum yang digunakan

Jadi, perhitungannya adalah:

$$
\begin{aligned}
\text { CSI } & =\frac{3,36}{5} \\
& =0,672
\end{aligned}
$$

Berdasarkan penelitian yang dilakukan terhadap 65 responden untuk mengetahui kepuasan pelanggan wika solar water heater pada CV Vania Jaya Plumbing dengan metode CSI, diperoleh hasil sebesar 0,672 atau $67,2 \%$ yang berarti pada kisaran antara 0,61-0,80. Berdasarkan hasil CSI tersebut, maka kualitas pelayanan yang diberikan karyawan CV Vania Jaya Plumbing kepada konsumen atau pelanggan berada pada level puas.

\section{Kesimpulan}

Berdasarkan hasil dan analisa dari kepuasan pelanggan wika solar water heater pada CV Vania Jaya Plumbing adalah hasil dari perhitungan Importance Performance Analysis terdapat beberapa atribut yang perlu dipertahankan (kuadran II) yaitu karyawan selalu berpenampilan rapi saat bekerja, peralatan yang digunakan bersih dalam proses pengerjaan, hasil pengerjaan tepat dan akurat. Terdapat juga atribut yang perlu diperbaiki (kuadran I) yaitu peralatan yang digunakan lengkap, proses dalam 
pembayaran mudah, karyawan siap membantu bila pelanggan mengalami kesulitan, karyawan cepat dalam memberian informasi yang dibutuhkan, paket harga yang ditawarkan terjangkau, karyawan ahli dalam bidangnya dan sudah berpengalaman. Serta terdapat atribut yang perlu dikurangi (Kuadran IV) yaitu petunjuk informasi tentang proses pendaftaran sudah jelas, biaya jasa yang ditawarkan sesuai dengan kualitas, karyawan menanyakan posisi peletakan wika solar water heater yang tepat dan sesuai dengan keingginan pelanggan, karyawan selalu menerapkan salam, senyum dan sapa dan hasil dari perhitungan Customer Satisfaction Index diperoleh hasil sebesar 0,672 atau $67,2 \%$ yang berarti pada kisaran antara 0,61-0,80. Berdasarkan hasil CSI tersebut, maka kualitas pelayanan pada CV Vania Jaya Plumbing tersebut merasa puas terhadap kualitas pelayanan yang diberikan oleh karyawan selama ini.

\section{Daftar Pustaka}

Armadi, D.A., Sasongko, H., dan Wihartika, D., 2019, Studi Kepuasan Pelanggan Terhadap Kinerja Jasa Layanan PDAM dengan Metode Importance performance analysis. e-ISSN: 2502-5678

Ayuni, N.W.D., Adiakas, I.M.A dan Sari, I.G.A.M.K.K., 2017, Analisis Kepuasan Pelanggan Terhadap Produk Kopi Bijik Salak. Bali: Politeknik Negeri Bali.

Chandra, T., dan Novia D., 2019, Analisis kualitas pelayanan dan kepuasan pelanggan menggunakan metode customer satisfaction index (CSI) dan Importance performance analysis (IPA) pada optic "JAKARTA" Optical Pekanbaru. e-ISSN 2580-3743.

Dwi M.N., 2015, Pengaruh Kualitas Pelayanan, Kualitas Produk Layanan, dan Harga Produk Layanan Terhadap Kepuasan Pelanggan Serta Dampaknya Terhadap Loyalitas Pelanggan Prabayar Telkomsel, Jurnal OE, 7(2), 58-174.

Fitra, 2017, Kinerja Pengelola Pasar Rakyat Desa Sintong Pusaka Kecamatan Tanah Putih Rokan Hilir, Prosiding Seminar Nasional Sekolah Tinggi Teknologi Dumai, Jilid 1, LPPM Sekolah Tinggi Teknologi Dumai.

Fitra, 2017, Pengukuran Kinerja Karyawan PT X di Kota Dumai, Jurnal UNITEk VOL 10 No.1.

Febrianti, Atika., Indriani, Sri dan Adriantantri, Emmalia, 2021, Pengukuran Kepuasan Penmpang Terhadap Pelayanan Jasa Penyebrangan Laut Dengan MEtode Servic Quality dan Importance performance analysis (Studi Kasus PT ASDP Indonesia Ferry (Persero) Cabang Singkil). e-ISSN: 2614-8382.

Indrajaya, D., 2018, Analisis Kualitas Pelayanan T erhadap Tingk at Kepuasan Konsumen Menggunakan Metode Importance performance analysis dan Customer satisfaction index Pada UKM Gallery. ISSN: 2580-4308

Komalig, Anastasya L., 2013, Manajemen Hubungan Pelanggan dan Promosi Pengaruhnya Terhadap Kepuasan Debitor Pada PT. Bank Sulut Cabang Calaca Manado. Jurnal EMBA vol.1 no.4 Desember 2013.

Kotler, Philip dan Keller, Kevin Lane, 2009, Manajemen Pemasaran, Diterjemehkan oleh Bob sabran. Jilid 1, Jakarta: Erlangga.

Melliana, Yusrizal, Mesra, T., dan Fitra, 2019, Tingkat Pelayanan Swalayan XYZ Terhadap Kepuasan Konsumen Di Kota Dumai, Talenta Conference Series: Energy and Engineering (EE), Vol 2 No 4. 
Melliana, Yusrizal, Mesra, T., dan Fitra, 2019, Tingkat Pelayanan Swalayan XYZ Terhadap Kepuasan Konsumen Di Kota Dumai, Talenta Conference Series: Energy and Engineering (EE), Vol 2 No 4.

Rahmadhani, Fahrizal Eka, 2017, Analisis Kualitas Pelayanan Jasa Untuk Mengetahui Kepuasan Pelanggan Nethost Menggunakan Metode Importance performance analysis. ISSN: 2355-9357.

Rondonuwu, Priscilia D, 2013, Kualitas Produk, Harga dan Kualitas Layanan Pengaruhnya Terhadap Kepuasan Konsumen Pengguna Mobil Nissan March Pada PT. Wahana Wirawan Manado. Jurnal EMBA vol.1 no.4 Desember 2013.

Sampurno, Hasna Rahagi dan Sharif, Osa Omar, 2020, Penerapan Customer satisfaction index (CSI) dan Importance performance analysis (IPA) Pada Kualitas Pelayanan Gojek (Studi Pelanggan di Kota Bandung). ISSN: 2614-0365.

Sangadji, E.M., dan Sopiah, 2013, Prilaku Konsumen: Pendekatan Praktis Disertai:Himpunan Jurnal Penelitian. Yogyakarta: Penerbit Andi.

Sugiyono, 2014, Metode Penelitian Kuantitatif, Kualitatif, dan R\&D. Bandung: Alfabeta.

Supranto, J, 2001, Pengukuran tingkat kepuasan pelanggan. Jakarta: Bineka Cipta.

Tjiptono, Fandy, 2008, Strategi Pemasaran, Edisi ke tiga, Andi.Yogyakarta

Utami, Ruli dan Atmojo, Suryo, 2017, Implementasi Metode Importance Performance Matrix Untuk Evaluasi dan Pengingkatan Pelayanan Perusahaan Jasa Care Cleaners. e-ISSN: $2503-2$ 